\title{
Unidades térmicas e produtividade em genótipos de milheto semeados em duas épocas
}

\author{
Antonio Carlos Torres da Costa ${ }^{(1)}$, José Geraldo(2), Maurício Ballesteiro Pereira( ${ }^{(3)}$ e Carlos Pimentel(1) $^{(1)}$
}

\begin{abstract}
(1)Universidade Federal Rural do Rio de Janeiro (UFRRJ), Instituto de Agronomia, Dep. de Fitotecnia, BR 465, Km 07, CEP 23890-000 Seropédica, RJ. E-mail: torres@ruralnet.com.br, greenman@amcham.com.br (2)UFRRJ, Colégio Técnico. E-mail: jgeraldo@ufrrj.br (3)UFRRJ, Instituto de Biologia, Dep. de Genética. E-mail: balleste@ufrrj.br
\end{abstract}

\begin{abstract}
Resumo - O objetivo deste trabalho foi avaliar o acúmulo de unidades térmicas (UT) e de biomassa em genótipos de milheto semeados nas águas e na seca, sem irrigação e adubação, em delineamento experimental de blocos ao acaso. Nas águas, o ciclo do BRS 1501 foi de 76 dias, com 1.239 UT, e ENA 1 teve ciclo de 82 dias, com 1.325 UT, sem diferenças de produtividade de biomassa e grãos. O genótipo Souna III acumulou 1.352 UT, com a maior produção de biomassa, mas não de grãos. Na floração, nessa época, BRS 1501 acumulou menos UT (517 UT) e menos biomassa, enquanto ENA 1 acumulou 545 UT e mais biomassa. Na seca, BRS 1501 teve ciclo de 80 dias, tendo requerido 1.123 UT, enquanto ENA 1 teve ciclo de 76 dias, com 1.074 UT; não houve diferença significativa na produção de biomassa e grãos. Na floração, nessa época, ENA 1 acumulou 447 UT e o BRS 1501, 461 UT. Não houve diferença no acúmulo de biomassa. O genótipo ENA 1 pode ser usado para a produção de biomassa, no sistema de plantio direto, e BRS 1501, para a produção de biomassa e de grãos, principalmente na seca.
\end{abstract}

Termos para indexação: Pennisetum glaucum, graus-dia, fases de desenvolvimento, biomassa, grãos.

\section{Thermal unities and yield of pearl millet genotypes sown in two seasons}

\begin{abstract}
The aim of this work was to evaluate the accumulation of thermal unities (TU) and biomass on pearl millet genotypes sown in rainy and dry seasons, without fertilization or irrigation, in a randomized complete block design. In the rainy season, the BRS 1501 cycle was 76 days, requiring 1,239 TU, while ENA 1 had a cycle of 82 days, with 1,325 TU, both with the same biomass and grain yield. The genotype Souna III accumulated 1,352 TU; its biomass yield was the highest. At flowering, in the rainy season, BRS 1501 accumulated 517 TU, with the lowest biomass, while ENA 1 accumulated 545 TU and higher biomass. At the dry season, BRS 1501 showed a cycle of 80 days, requiring 1,123 TU, while ENA 1 had a cycle of 76 days, with 1,074 TU, with no significant difference for biomass and grain yield. At flowering, in this season, ENA 1 and BRS 1501 accumulated $447 \mathrm{TU}$ and $461 \mathrm{TU}$, respectively, and there was no significant difference for biomass. The genotype ENA 1 can be used for biomass production for minimal tillering cultivation, and BRS 1501, for biomass and grain production, especially in the dry season.
\end{abstract}

Index terms: Pennisetum glaucum, day degrees, growth stages, biomass, grain.

\section{Introdução}

A cultura do milheto (Pennisetum glaucum (L.) R. Br.) é de fácil instalação e requer poucos insumos, pois a planta tem um sistema radicular profundo e vigoroso, o que a torna eficiente no uso de água e nutrientes (Payne, 2000). Por isto, em regiões marginais e áridas da África e Ásia, essa espécie adquire importância como cereal de subsistência humana (Bidinger \& Raju, 2000; Bruck et al., 2000).

Segundo Maiti \& Bidinger (1981), o milheto é originário do Sub-Saara africano, cultivado desde 3.000 a.C., de onde foi levado para a Índia a partir de 2.000 a.C., tendo gerado genótipos distintos dos originais africanos. Os genótipos africanos têm uma taxa de crescimento de cultura superior, são mais altos, mas perfilham menos e têm menor índice de colheita que os genótipos indianos, porém ambos têm o mesmo potencial produtivo (Norman et al., 1995).

Atualmente, o uso do milheto na agricultura brasileira vem aumentando rapidamente, para a produção de palhada no sistema de plantio direto, cada vez mais empregado no Cerrado. A definição de espécies com elevada produtividade de biomassa para cobertura do 
solo é um dos fatores de sucesso no plantio direto e, por isso, o milheto vem sendo cada vez mais utilizado nesse sistema agrícola (Oliveira et al., 2002). Além disto, o milheto pode também ser usado na produção de forragem, no pastejo ou silagem (Netto, 1998), e na produção de grãos usados no fabrico de rações animais, em virtude do seu baixo custo e boa qualidade (Rodrigues et al., 2001). Pode, ainda, ser alternativa alimentar humana em áreas de baixa precipitação pluvial (Bidinger \& Raju, 2000; Winkel et al., 2001), como o Nordeste. No Brasil, o milheto, considerado uma planta de dias curtos (Norman et al., 1995), tem sido semeado em duas épocas: no final do inverno/início da primavera e após a cultura de verão (safrinha) (Netto, 1998; Geraldo et al., 2002). Entretanto, deve-se ressaltar que a semeadura tardia do milheto, na segunda época de semeadura (safrinha), pode ser desaconselhável, pois a produção de forragem, por exemplo, coincide com o outono, época em que a velocidade de crescimento dos genótipos de milheto é menor (Guideli et al., 2000).

A duração das fases fenológicas, assim como a produtividade de uma cultura, varia entre regiões, anos e datas de semeadura, em razão das variações dos fatores climáticos (Gadioli et al., 2000). A temperatura tem-se mostrado um dos fatores climáticos mais importantes na predição dos eventos fenológicos de uma cultura, desde que não haja deficiência hídrica. Isto porque a temperatura média do ar, numa escala diária, afeta a quantidade de energia química produzida pela respiração do material genético, e cada espécie vegetal ou variedade possui uma temperatura base mínima para o crescimento, que pode variar em função da fase fenológica da planta (Pereira et al., 2002). Entretanto, é comum adotar-se uma única temperatura base durante todo o ciclo da planta, por ser mais fácil a sua aplicação. De acordo com Norman et al. (1995), a temperatura base para o milheto é de $10^{\circ} \mathrm{C}$.

$\mathrm{O}$ conhecimento das exigências térmicas, desde a emergência até o ponto de maturação fisiológica, é fundamental para a previsão da duração do ciclo da cultura, em função do ambiente (Gadioli et al., 2000). Essas informações, associadas ao conhecimento do acúmulo de biomassa da cultura, podem ser utilizadas no planejamento para definição da época de semeadura adequada, da utilização de insumos, da época de colheita (colheita de grãos ou momento de corte para silagem) e na recomendação de uso agrícola dos diferentes genótipos (Geraldo et al., 2000; Guideli et al., 2000).

Este trabalho teve como objetivo avaliar o efeito da época de semeadura na fenologia, nas unidades térmicas e na produção de biomassa e de grãos de genótipos de milheto, com vistas à sua indicação como material com potencial para a produção de cobertura morta, a ser empregada no sistema de plantio direto.

\section{Material e Métodos}

Dois experimentos foram conduzidos no Campo Experimental do Departamento de Fitotecnia, da Universidade Federal Rural do Rio de Janeiro, Município de Seropédica, RJ. O primeiro experimento foi instalado no mês de janeiro de 2002, no plantio das águas, em um Planossolo.

As análises químicas desse solo de textura arenosa, na camada de $0-20 \mathrm{~cm}$, revelaram: $\mathrm{pH}$ em água, 5,4; Ca, 1,5 $\mathrm{mmol}_{\mathrm{C}} \mathrm{dm}^{-3} ; \mathrm{Mg}, 0,6 \mathrm{mmol}_{\mathrm{C}} \mathrm{dm}^{-3} ; \mathrm{Al}$, $0,0 \mathrm{mmol}_{\mathrm{C}} \mathrm{dm}^{-3} ; \mathrm{H}, 1,5 \mathrm{mmol}_{\mathrm{C}} \mathrm{dm}^{-3} ; \mathrm{P}, 12,0 \mathrm{mg} \mathrm{dm}^{-3} ; \mathrm{K}$, $51,0 \mathrm{mg} \mathrm{dm}^{-3}$; matéria orgânica, $1,03 \mathrm{~g} \mathrm{~kg}^{-1}$; e saturação de bases $(\mathrm{V}), 59 \%$. A precipitação total, a evaporação total e a temperatura média, durante o experimento, foram de $336 \mathrm{~mm}, 352,2 \mathrm{~mm}$ e $26^{\circ} \mathrm{C}$, respectivamente.

O delineamento experimental utilizado foi o de blocos ao acaso, com cinco tratamentos (genótipos) e seis repetições. Foram utilizados três genótipos africanos produtores de grãos (HKP, Guerguera e Souna III) e dois outros genótipos selecionados no Brasil (BRS 1501 e ENA 1). Cada bloco teve $17 \mathrm{~m}$ de comprimento, por $2,5 \mathrm{~m}$ de largura e o espaçamento entre blocos e entre as parcelas foi de $0,5 \mathrm{~m}$. Cada parcela teve $3 \mathrm{~m}$ de comprimento por 2,5 m de largura, numa área total de $7,50 \mathrm{~m}^{2}$, e uma área útil de $3 \mathrm{~m}^{2}$, e foi constituída por 30 plantas, distribuídas em 5 linhas, com 12 plantas úteis, tendo o experimento uma área total de $225 \mathrm{~m}^{2}$ e área útil de $90 \mathrm{~m}^{2}$.

O segundo experimento foi instalado no mês de março de 2002, no plantio da seca, em um Planossolo. As análises químicas desse solo com textura arenosa, na camada de $0-20 \mathrm{~cm}$, revelaram: $\mathrm{pH}$ em água, 5,8; Ca, $0,5 \mathrm{mmol}_{\mathrm{C}} \mathrm{dm}^{-3} ; \mathrm{Mg}, 0,4 \mathrm{mmol}_{\mathrm{C}} \mathrm{dm}^{-3} ; \mathrm{Al}$, $0,0 \mathrm{mmol}_{\mathrm{C}} \mathrm{dm}^{-3} ; \mathrm{H}, 1,6 \mathrm{mmol}_{\mathrm{C}} \mathrm{dm}^{-3} ; \mathrm{P}, 16,0 \mathrm{mg} \mathrm{dm}^{-3} ; \mathrm{K}$, $51,0 \mathrm{mg} \mathrm{dm}^{-3}$; matéria orgânica, $1,29 \mathrm{~g} \mathrm{~kg}^{-1}$; e saturação de bases $(\mathrm{V}), 39 \%$. A precipitação total, a evaporação total e a temperatura média, durante o experimento, foram de $207,5 \mathrm{~mm}, 318,1 \mathrm{~mm}$ e $24,4^{\circ} \mathrm{C}$, respectivamente. Foi empregado o delineamento experimental de blocos ao acaso, com cinco tratamentos (genótipos) e quatro repetições (nesse plantio houve um menor número de repetições do que no plantio das águas, devido à limitação de sementes). Foram utilizados os mesmos cinco genótipos avaliados no primeiro experimento. Cada bloco teve 23,5 m de comprimento por 2,5 m de largura, e o espaçamento entre blocos e entre as parcelas foi de $0,5 \mathrm{~m}$. Cada parcela teve $3,5 \mathrm{~m}$ de comprimento por 2,5 m de largura, numa área total de $8,75 \mathrm{~m}^{2}$, e área útil de $3,75 \mathrm{~m}^{2}$; foi constituída por 35 plantas, distribuídas em 5 linhas, com 15 plantas úteis, tendo o experimento área total de $168 \mathrm{~m}^{2} \mathrm{e}$ área útil de $72 \mathrm{~m}^{2}$. 
As sementes dos genótipos africanos produtores de grãos (HKP, Guerguera e Souna III) foram obtidas por meio de um convênio da Universidade Federal Rural do Rio de Janeiro com o Centre d'Étude Régional pour l'Amériolation de l'Adaptation à la Sécheresse (CERAAS, Bambey, Senegal). O genótipo da Embrapa (BRS 1501) foi fornecido pela Embrapa Milho e Sorgo, em Sete Lagoas, MG. As sementes do genótipo ENA 1 foram obtidas do cruzamento natural e da seleção feita na época das águas, a partir dos genótipos africanos citados acima (Geraldo et al., 2002).

Nos dois experimentos, após o preparo do solo, o plantio foi feito com espaçamento de $0,5 \mathrm{~m}$ entre linhas e $0,5 \mathrm{~m}$ entre plantas na linha, com um desbaste após dez dias, permanecendo uma planta por cova. Os experimentos foram conduzidos sem adubação e irrigação, e os tratos culturais consistiram em capinas manuais.

Nos dois experimentos, todas as parcelas foram constituídas de cinco linhas (30 plantas), e as duas linhas laterais de cada parcela, assim como a primeira planta de cada uma das três linhas centrais, foram utilizadas como bordaduras. As três linhas centrais de cada parcela (12 plantas úteis) foram utilizadas para avaliar os estádios e fases de desenvolvimento de cada genótipo, conforme Maiti \& Bidinger (1981). Considerou-se que determinado estádio havia sido alcançado, quando as características desse estádio foram observadas em $50 \%$ do conjunto das plantas avaliadas.

Na caracterização dos estádios e fases de desenvolvimento, os experimentos tiveram acompanhamento diário, desde o plantio até a colheita. Além disso, com os dados de temperatura média diária, registradas no posto da Estação Experimental de
Seropédica, da Pesagro, RJ, determinaram-se, em todos os genótipos, as unidades térmicas (UT) necessárias para completar cada estádio e fase de desenvolvimento, de acordo com Pereira et al. (2002). Para isso, utilizou-se a fórmula UT $=\Sigma$ (temperatura média diária - temperatura base) em ${ }^{\circ} \mathrm{C}$, por dia. A temperatura base utilizada foi de $10^{\circ} \mathrm{C}$ (Norman et al., 1995).

Nos dois experimentos, em quatro plantas centrais $\left(1 \mathrm{~m}^{2}\right)$ de cada parcela com cinco linhas, foi avaliada a produção de matéria verde e seca da parte aérea, no estádio de florescimento, numa linha adjacente à uma das bordaduras. Em outras quatro plantas, da linha adjacente à outra bordadura da parcela, foi feita a avaliação da produção de matéria verde e seca da parte aérea e produção de grãos, no final do ciclo. Quando se aproximou a maturação dos grãos, toda a área experimental foi coberta com uma tela para evitar o ataque de pássaros.

A análise estatística foi realizada segundo o modelo de blocos ao acaso, para os dados de produção de matéria verde e seca da parte aérea e de grãos, enquanto na avaliação dos estádios e fases de desenvolvimento não foi feita análise estatística, pois a duração dos estádios foi determinada quando 50\% de todas as plantas daquele genótipo, em todos os blocos, atingiam o estádio. Nos dados de produção, a comparação entre as médias foi feita pelo teste de Student-Newman-Keuls, a 5\% de probabilidade.

\section{Resultados e Discussão}

O ciclo da cultura foi mais longo no plantio das águas que no da seca, exceto para o genótipo BRS 1501 (Tabelas 1 e 2). Isto mostra menor sensibilidade do BRS 1501 ao

Tabela 1. Dias após a emergência (DAE) e quantidade de unidades térmicas (UT) para iniciar e completar, respectivamente, os estádios e fases de desenvolvimento nos genótipos de milheto, semeados na época das águas.

\begin{tabular}{|c|c|c|c|c|c|c|c|c|c|c|}
\hline \multirow{2}{*}{$\begin{array}{l}\text { Estádio (E) e fase (Gs) } \\
\text { do desenvolvimento }^{(1)}\end{array}$} & \multicolumn{2}{|c|}{ Guerguera } & \multicolumn{2}{|c|}{ HKP } & \multicolumn{2}{|c|}{ Souna III } & \multicolumn{2}{|c|}{ ENA 1} & \multicolumn{2}{|c|}{ BRS 1501} \\
\hline & DAE & UT & DAE & UT & DAE & UT & DAE & UT & DAE & UT \\
\hline E0 & 0 & 31 & 0 & 31 & 0 & 31 & 0 & 31 & 0 & 31 \\
\hline E1 & 6 & 111 & 6 & 111 & 7 & 129 & 6 & 111 & 7 & 129 \\
\hline $\mathrm{E} 2$ & 10 & 178 & 10 & 178 & 12 & 214 & 10 & 178 & 11 & 196 \\
\hline E3 & 34 & 559 & 33 & 545 & 37 & 602 & 33 & 545 & 31 & 517 \\
\hline $\mathrm{E} 4$ & 47 & 753 & 43 & 687 & 50 & 803 & 47 & 753 & 42 & 672 \\
\hline E5 & 54 & 875 & 49 & 785 & 54 & 875 & 52 & 839 & 48 & 769 \\
\hline E6 & 59 & 961 & 55 & 892 & 61 & 994 & 59 & 961 & 55 & 892 \\
\hline E7 & 67 & 1.094 & 62 & 1.013 & 67 & 1.094 & 65 & 1.067 & 60 & 977 \\
\hline E8 & 74 & 1.204 & 69 & 1.125 & 76 & 1.239 & 73 & 1.188 & 67 & 1.094 \\
\hline E9 & 82 & 1.325 & 78 & 1.272 & 84 & 1.352 & 82 & 1.325 & 76 & 1.239 \\
\hline Gs1 & 34 & 559 & 33 & 545 & 37 & 602 & 33 & 545 & 31 & 517 \\
\hline Gs2 & 25 & 402 & 22 & 347 & 24 & 393 & 26 & 416 & 24 & 376 \\
\hline Gs3 & 23 & 364 & 23 & 379 & 23 & 358 & 23 & 364 & 21 & 347 \\
\hline
\end{tabular}

(1)E0: coleóptilo visível na superfície do solo; E1: terceira folha visível; E2: quinta folha visível; E3: início de formação da panícula; E4: folha bandeira visível; E5: panícula visível; E6: 50\% dos estigmas emergidos; E7: estádio do grão leitoso; E8: estádio do grão pastoso; E9: maturação fisiológica; Gs1: fase vegetativa (E1 a E3); Gs2: fase de floração (E4 a E6); Gs3: fase de enchimento do grão (E7 a E9) (segundo Maiti \& Bidinger, 1981). 
fotoperíodo. Entre os outros genótipos avaliados, o Souna III, no plantio de janeiro, apresentou ciclo mais longo (Tabela 1), tendo necessitado de mais UT, enquanto, no plantio de março, apresentou ciclo mais curto, com menor necessidade de UT (Tabela 2), o que caracteriza esse genótipo como o mais sensível ao fotoperíodo. O genótipo ENA 1 apresentou comportamento similar ao do Souna III, um de seus progenitores.

A redução do ciclo da cultura, no plantio de março em relação ao de janeiro (exceto para o genótipo BRS 1501), pode ser atribuída principalmente ao efeito do fotoperíodo (Maiti \& Bidinger, 1981), mas também está associada ao balanço hídrico mais desfavorável nessa época de cultivo $(-107 \mathrm{~mm})$, em relação ao de janeiro (-16 mm). De acordo com Pereira et al. (2002), o tempo necessário para atingir determinado estádio fenológico é controlado pelas temperaturas médias diárias do ambiente, caso não haja falta de água, e é característico à espécie, e dentro da espécie, às cultivares, sendo determinante na duração do ciclo da cultura.

No plantio das águas, em janeiro, o genótipo BRS 1501 teve a fase vegetativa (Gs1) mais curta, em torno de 31 dias, com 517 UT, enquanto o genótipo Souna III apresentou Gs1 um pouco mais longa, em torno de 37 dias, com 602 UT (Tabela 1). Já o genótipo ENA 1 apresentou a mais longa fase de floração (Gs2), em torno de 26 dias, com 416 UT, e o genótipo HKP apresentou a mais curta Gs2, em torno de 22 dias, com 347 UT. O genótipo Souna III necessitou de 17 UT a mais do que o genótipo BRS 1501, para completar essa fase (Tabela 1). Os genótipos HKP, Guerguera, Souna III e ENA 1 apresentaram a mais longa fase de enchimento do grão (Gs3), em torno de 23 dias. Entretanto, o genótipo HKP necessitou de 21 UT a mais do que o genótipo Souna III, para completar essa fase. O genótipo BRS 1501 apresentou a mais curta Gs3, em torno de 21 dias, com 347 UT (Tabela 1).

No plantio da seca, em março, a Gs1 foi semelhante entre os genótipos (Tabela 2), tendo variado de 27 a 28 dias, com 447 a 461 UT. O genótipo BRS 1501 apresentou Gs2 mais longa (Tabela 2), com aproximadamente 25 dias e 347 UT, enquanto o genótipo Souna III teve menor Gs2, com aproximadamente 20 dias e 282 UT. Já a duração da Gs3 teve pequena variação entre os genótipos estudados (Tabela 2), com duração de 24 a 27 dias, e acúmulo de 282 a 314 UT. Os resultados obtidos nas duas épocas de plantio estão de acordo com Netto (1998), ao relatar que a Gs1 do milheto varia de 27 a 39 dias, a Gs2 varia de 11 a 32 dias e a Gs3 varia de 19 a 22 dias.

No plantio das águas, em janeiro, houve diferenças significativas entre os genótipos, para a produção de biomassa (Tabela 3), obtida na fase de floração (Gs2) e na de maturação fisiológica (Gs3). Quanto à produção de matéria verde, obtida na fase Gs2, os genótipos Guerguera, ENA 1 e Souna III diferiram estatisticamente do genótipo BRS 1501, embora este não tenha diferido estatisticamente do genótipo HKP (Tabela 3). A baixa produção de biomassa na floração, do genótipo BRS 1501, pode ser atribuída à menor duração da sua

Tabela 2. Dias após a emergência (DAE) e quantidade de unidades térmicas (UT) para iniciar e completar, respectivamente, os estádios e fases de desenvolvimento nos genótipos de milheto, semeados na época da seca.

\begin{tabular}{|c|c|c|c|c|c|c|c|c|c|c|}
\hline \multirow{2}{*}{$\begin{array}{l}\text { Estádio (E) e fase (Gs) } \\
\text { do desenvolvimento }^{(1)}\end{array}$} & \multicolumn{2}{|c|}{ Guerguera } & \multicolumn{2}{|c|}{ HKP } & \multicolumn{2}{|c|}{ Souna III } & \multicolumn{2}{|c|}{ ENA 1} & \multicolumn{2}{|c|}{ BRS 1501} \\
\hline & DAE & UT & DAE & UT & DAE & UT & DAE & UT & DAE & UT \\
\hline E0 & 0 & 36 & 0 & 36 & 0 & 36 & 0 & 36 & 0 & 36 \\
\hline E1 & 5 & 117 & 5 & 117 & 6 & 133 & 5 & 117 & 6 & 133 \\
\hline $\mathrm{E} 2$ & 11 & 211 & 10 & 194 & 12 & 227 & 10 & 194 & 11 & 211 \\
\hline E3 & 28 & 461 & 27 & 447 & 27 & 447 & 27 & 447 & 28 & 461 \\
\hline $\mathrm{E} 4$ & 39 & 622 & 38 & 607 & 37 & 592 & 40 & 636 & 39 & 622 \\
\hline E5 & 44 & 691 & 43 & 678 & 41 & 648 & 44 & 691 & 47 & 729 \\
\hline E6 & 51 & 784 & 49 & 756 & 47 & 729 & 51 & 784 & 53 & 808 \\
\hline E7 & 62 & 932 & 61 & 918 & 57 & 862 & 59 & 894 & 61 & 918 \\
\hline E8 & 69 & 1.019 & 68 & 992 & 66 & 977 & 67 & 985 & 70 & 1.010 \\
\hline E9 & 77 & 1.086 & 74 & 1.052 & 74 & 1.052 & 76 & 1.074 & 80 & 1.123 \\
\hline Gs1 & 28 & 461 & 27 & 447 & 27 & 447 & 27 & 447 & 28 & 461 \\
\hline Gs2 & 23 & 323 & 22 & 309 & 20 & 282 & 24 & 337 & 25 & 347 \\
\hline Gs3 & 26 & 302 & 25 & 296 & 24 & 323 & 25 & 290 & 27 & 314 \\
\hline
\end{tabular}

(1)E0: coleóptilo visível na superfície do solo; E1: terceira folha visível; E2: quinta folha visível; E3: início de formação da panícula; E4: folha bandeira visível; E5: panícula visível; E6: 50\% dos estigmas emergidos; E7: estádio do grão leitoso; E8: estádio do grão pastoso; E9: maturação fisiológica; Gs1: fase vegetativa (E1 a E3); Gs2: fase de floração (E4 a E6); Gs3: fase de enchimento do grão (E7 a E9) (segundo Maiti \& Bidinger, 1981). 
fase vegetativa (Tabela 1) e menor taxa de crescimento de cultura (Norman et al., 1995). Portanto, para a produção de biomassa na floração, no plantio das águas, para o plantio direto, forragem e silagem, os genótipos Guerguera, ENA 1 e Souna III são mais produtivos que o BRS 1501.

Ainda no plantio das águas, em relação à produção de matéria verde, obtida no final da maturação, fase Gs3, os genótipos ENA 1 e BRS 1501 não diferiram estatisticamente entre si. Contudo, o genótipo Souna III foi o mais produtivo, tendo diferido estatisticamente dos demais genótipos, e o genótipo HKP foi o menos produtivo (Tabela 3). Quanto à produção de matéria seca obtida nessa fase Gs3, o genótipo Souna III, apesar de não diferir estatisticamente do genótipo Guerguera, foi o mais produtivo, tendo diferido dos demais. O genótipo HKP, apesar de não diferir estatisticamente dos genótipos ENA 1 e BRS 1501, teve baixa produção de matéria seca. Tais resultados são superiores aos obtidos por Maia et al. (2000), que verificaram rendimentos acima de $4 \mathrm{t} \mathrm{ha}^{-1}$, e inferiores aos verificados por Lupatini et al. (1996) e Oliveira et al. (2002), que obtiveram rendimentos acima de $10 \mathrm{t} \mathrm{ha}^{-1}$ de matéria seca - trabalhos conduzidos com adubação.

Quanto à produção de grãos, nesse plantio das águas, não houve diferenças significativas entre os genótipos (Tabela 3). Nesse plantio, feito em janeiro, obtiveram-se rendimentos de aproximadamente $3 \mathrm{t} \mathrm{ha}^{-1}$ de grãos, porém sem adubação, em um solo com baixo teor de carbono. Isso mostra que o milheto é eficiente na aquisição de nutrientes, e pode beneficiar-se do resíduo de fertilizantes ou do $\mathrm{N}$ fixado por leguminosas, de um plantio anterior (Netto, 1998; Payne, 2000).
Maiti \& Bidinger (1981) e Geraldo et al. (2000, 2002) observaram um aumento de matéria seca de parte aérea, entre a floração e a maturação, o que mostra uma manutenção do crescimento e da acumulação de biomassa vegetativa, após a floração do milheto. Isso também foi observado neste experimento; dentre os genótipos estudados, o aumento foi mais acentuado no BRS 1501 que, entre a floração e a maturação, apresentou um incremento de biomassa (Tabela 3). No genótipo BRS 1501, a maioria dos perfilhos acompanha o crescimento do colmo principal e atinge um tamanho muito próximo a este, permitindo assim um grande acúmulo de matéria seca, após a floração do colmo principal. Ao contrário, nos genótipos africanos, apesar de o colmo principal atingir uma altura considerável, a maioria dos seus perfilhos permanece com tamanho inferior. Nesse plantio das águas, o genótipo ENA 1 apresentou, em média, cinco perfilhos por planta, com uma altura do colmo principal de 2,15 m, enquanto o BRS 1501 teve, em média, sete perfilhos por planta, com uma altura do colmo principal de 1,44 m. Portanto, para a obtenção de biomassa e grãos, no final do ciclo no plantio das águas, não houve diferença entre os genótipos estudados.

No plantio da seca, em março (safrinha), houve diferenças significativas entre os genótipos na produção de biomassa obtida na fase Gs2 (Tabela 3). Os genótipos Souna III e Guerguera diferiram estatisticamente do genótipo ENA 1, tanto em matéria verde quanto em matéria seca, mas não diferiram dos genótipos HKP e BRS 1501. Esses dois últimos tiveram produção de matéria seca semelhante ao ENA 1. Nessa época de cultivo (safrinha), não houve diferenças significativas entre os genótipos para a produção de biomassa e de grãos, obtidas na maturação. Deve-se ressaltar que,

Tabela 3. Produção de matéria verde e seca da parte aérea, na floração e na maturação fisiológica, e produção de grãos de genótipos de milheto, semeados na época das águas e da seca(1).

\begin{tabular}{|c|c|c|c|c|c|}
\hline Genótipo & $\begin{array}{l}\text { Matéria verde na floração } \\
\left(\mathrm{kg} \mathrm{ha}^{-1}\right)\end{array}$ & $\begin{array}{l}\text { Matéria seca na floração } \\
\left(\mathrm{kg} \mathrm{ha}^{-1}\right)\end{array}$ & $\begin{array}{l}\text { Matéria verde na maturação } \\
\text { fisiológica }\left(\mathrm{kg} \mathrm{ha}^{-1}\right)\end{array}$ & $\begin{array}{l}\text { Matéria seca na maturação } \\
\text { fisiológica }\left(\mathrm{kg} \mathrm{ha}^{-1}\right)\end{array}$ & $\begin{array}{l}\text { Produção de grãos } \\
\left(\mathrm{kg} \mathrm{ha}^{-1}\right)\end{array}$ \\
\hline & & & Águas & & \\
\hline Guerguera & $34.300 \mathrm{a}$ & $7.749 \mathrm{a}$ & $22.520 \mathrm{~b}$ & $7.957 \mathrm{ab}$ & $2.965 \mathrm{a}$ \\
\hline HKP & $25.250 \mathrm{ab}$ & $6.657 \mathrm{a}$ & $16.710 \mathrm{~d}$ & $6.688 \mathrm{~b}$ & $2.532 \mathrm{a}$ \\
\hline Souna III & $28.250 \mathrm{a}$ & $6.817 \mathrm{a}$ & $24.580 \mathrm{a}$ & $8.396 \mathrm{a}$ & $3.232 \mathrm{a}$ \\
\hline ENA 1 & $32.300 \mathrm{a}$ & $6.996 \mathrm{a}$ & $19.300 \mathrm{c}$ & $7.027 \mathrm{~b}$ & $2.627 \mathrm{a}$ \\
\hline BRS 1501 & $18.350 \mathrm{~b}$ & $4.458 \mathrm{~b}$ & $19.590 \mathrm{c}$ & $7.025 \mathrm{~b}$ & $2.767 \mathrm{a}$ \\
\hline $\mathrm{CV}(\%)$ & 22,22 & 23,12 & 6,32 & 10,87 & 22,52 \\
\hline Guerguera & $7.225 \mathrm{ab}$ & $1.151 \mathrm{~b}$ & $\begin{array}{l}\text { Seca } \\
3.900 \mathrm{a}\end{array}$ & $1.670 \mathrm{a}$ & $630 \mathrm{a}$ \\
\hline HKP & $8.563 \mathrm{ab}$ & $1.457 \mathrm{ab}$ & $\begin{array}{l}3.900 \mathrm{a} \\
4.400 \mathrm{a}\end{array}$ & $\begin{array}{l}1.07 / \mathrm{d} \\
1.950 \mathrm{a}\end{array}$ & $613 a$ \\
\hline Souna III & $6.825 b$ & $1.146 \mathrm{~b}$ & $4.350 \mathrm{a}$ & $1.765 \mathrm{a}$ & $970 \mathrm{a}$ \\
\hline ENA 1 & $11.280 \mathrm{a}$ & $1.878 \mathrm{a}$ & $5.375 \mathrm{a}$ & $2.110 \mathrm{a}$ & $810 \mathrm{a}$ \\
\hline BRS 1501 & $9.913 \mathrm{a}$ & $1.479 \mathrm{ab}$ & $5.575 \mathrm{a}$ & $2.460 \mathrm{a}$ & $1.103 \mathrm{a}$ \\
\hline $\mathrm{CV}(\%)$ & 21,04 & 18,28 & 18,91 & 23,53 & 30,31 \\
\hline
\end{tabular}

(1)Médias seguidas da mesma letra, na coluna, não diferem entre si a 5\% de probabilidade, pelo teste de Student-Newman-Keuls. 
apesar do balanço hídrico mais desfavorável nesse plantio da seca, quando comparado ao plantio das águas, houve uma boa precipitação nesse plantio (207,5 mm), que permitiu a obtenção de alta produtividade para a época.

Ainda nesse plantio da seca, como no das águas, também houve aumento de matéria seca de parte aérea, entre a floração e a maturação. Tal aumento, como no plantio das águas, foi também mais acentuado no genótipo BRS 1501 que, entre a floração e a maturação, apresentou aumento de matéria seca, seguido do genótipo Souna III (Tabela 3).

Comparando-se a produção de biomassa e de grãos nos dois experimentos, as baixas produções de biomassa e de grãos dos genótipos avaliados, na segunda época de semeadura, foram decorrentes do efeito negativo do fotoperíodo e do termoperíodo; e da incidência da ferrugem, que é maior no inverno (Tapsoba \& Wilson, 1997), associada ao balanço hídrico mais desfavorável no cultivo de março $(-107 \mathrm{~mm})$, em relação ao de janeiro (-16 m), o que confirma os resultados de Guideli et al. (2000). Isto pode explicar a menor produtividade, obtida na segunda época de semeadura, pois houve um período de falta de água dos 24 aos 42 dias depois da emergência, o que coincidiu com o início da formação da panícula (E3) (Tabela 2). Além disso, houve um segundo período de falta de água, dos 50 aos 64 dias depois da emergência, que coincidiu com o florescimento (E6). A fase de florescimento e de polinização é um período crítico para a cultura, pois nesse momento ocorre um aumento da atividade fotossintética nas folhas, que visa a acumular carboidratos e garantir o crescimento do embrião. Caso ocorra falta de água nesse período, como ocorreu no plantio da seca, há redução na fotossítese e na produtividade (Pimentel et al., 1999).

As mesmas diferenças para as características morfológicas observadas no plantio das águas, entre os genótipos ENA 1 e BRS 1501, foram confirmadas no plantio da seca, mas com valores mais baixos do que nas águas. Nesse plantio da seca, o genótipo ENA 1 apresentou, em média, cinco perfilhos por planta, com altura do colmo principal de 1,38 m, enquanto o BRS 1501 teve, em média, seis perfilhos por planta, com altura do colmo principal de $1 \mathrm{~m}$.

Ao se comparar a produção de matéria verde na floração e na maturação, e a produção de grãos, nos dois plantios, pode-se afirmar que, na produção de biomassa nas águas, para uso no sistema de plantio direto, forragem ou silagem, o genótipo ENA 1 teve maior produção de matéria verde e seca na floração, e igual produção, tanto de biomassa quanto de grãos, na maturação, quando comparado ao BRS 1501.

Conforme Payne (2000) e Winkel et al. (2001), para a safrinha, plantio da seca, o BRS 1501, apesar de não diferir estatisticamente da produção de biomassa e de grãos do ENA 1, deverá apresentar maior estabilidade de produção, pois apresenta maior número de perfilhos, o que é desejável, pois se algum estresse impedir o desenvolvimento de um dos perfilhos, haverão outros para manter a produtividade.

Outrossim, quando comparados o crescimento vegetativo, a altura das plantas e o número de perfilhos, nesses dois genótipos, segundo Norman et al. (1995), o ENA 1 teve um comportamento de genótipos africanos, e o BRS 1501, o de indianos, o que é importante para se manter uma alta diversidade genética para a cultura do milheto pérola no Brasil.

\section{Conclusões}

1. A duração do ciclo da cultura, a quantidade de unidades térmicas necessárias e a produção de biomassa e de grãos são maiores no plantio das águas que no da seca, exceto para o genótipo BRS 1501.

2. O genótipo ENA 1 produz mais biomassa na floração e pode ser considerado um material com potencial para cobertura morta, para uso no sistema de plantio direto nas águas, e o BRS 1501, para a produção de biomassa e de grãos, principalmente no plantio da seca.

\section{Referências}

BIDINGER, F.R.; RAJU, D.S. Response to selection for increased individual grain mass in pearl millet. Crop Science, v.40, p.68-71, 2000.

BRÜCK, H.; PAYNE, W.A.; SATTELMACHER, B. Effects of phosphorus and water supply on yield, transpirational water-use efficiency, and carbon isotope discrimination of pearl millet. Crop Science, v.40, p.120-125, 2000.

GADIOLI, J.L.; DOURADO-NETO, D.; GARCIA, A.G. y; BASANTA, M.V. Temperatura do ar, rendimento de grãos de milho e caracterização fenológica associada à soma calórica. Scientia Agricola, v.57, p.377-383, 2000.

GERALDO, J.; OLIVEIRA, L.D. de; PEREIRA, M.B.; PIMENTEL, C. Fenologia e produção de massa seca e de grãos em cultivares de milheto-pérola. Pesquisa Agropecuária Brasileira, v.37, p.12631268, 2002. 
GERALDO, J.; ROSSIELLO, R.O.P.; ARAÚJO, A.P.; PIMENTEL, C. Diferenças em crescimento e produção de grãos entre quatro cultivares de milheto pérola. Pesquisa Agropecuária Brasileira, v.35, p.1367-1376, 2000.

GUIDELI, C.; FAVORETTO, V.; MALHEIROS, E.B. Produção e qualidade do milheto semeado em duas épocas e adubado com nitrogênio. Pesquisa Agropecuária Brasileira, v.35, p.2093-2098, 2000.

LUPATINI, G.C.; MOOJEN, E.L.; RESTLE, J.; SILVA, J.H.S. da. Resposta do milheto (Pennisetum americanum (L.) Leeke) sob pastejo à adubação nitrogenada. Pesquisa Agropecuária Brasileira, v.31, p.715-720, 1996.

MAIA, M.C.; PINTO, J.C.; ANDRADE, I.F. de. Estabelecimento de pastagem de capim-tanzânia usando milheto como cultura acompanhante. Revista Brasileira de Zootecnia, v.29, p.13121319, 2000.

MAITI, R.K.; BIDINGER, F.R. Growth and development of the pearl millet plant. Patancheru: International Crops Research Institute for the Semi-Arid Tropics, 1981. 14p. (Research bulletin, 6).

NETTO, D.A.M. A cultura do milheto. Sete Lagoas: EmbrapaCNPMS, 1998. 6p. (Comunicado técnico, 11).

NORMAN, M.J.T.; PEARSON, C.J.; SEARLE, P.G.E. Pearl millet (Pennisetum glaucum). In: NORMAN, M.J.T.; PEARSON, C.J.; SEARLE, P.G.E. (Ed.). The ecology of tropical food crops. Cambridge, Inglaterra: Cambridge University Press, 1995. p.164-184.
OLIVEIRA, T.K. de; CARVALHO, G.J. de; MORAES, R.N. de S. Plantas de cobertura e seus efeitos sobre o feijoeiro em plantio direto. Pesquisa Agropecuária Brasileira, v.37, p.1079-1087, 2002.

PAYNE, W.A. Optimizing crop water use in sparse stands of pearl millet. Agronomy Journal, v.92, p.808-814, 2000.

PEREIRA, A.R.; ANGELOCCI, L.R.; SENTELHAS, P.C. Agrometeorologia, fundamentos e aplicações práticas. Guaíba: Agropecuária, 2002. 478p.

PIMENTEL, C.; HÉBERT, G.; SILVA, J.V. da. Effects of drought on $\mathrm{O}_{2}$ evolution capacity and stomatal conductance of beans at the pollination stage. Environmental and Experimental Botany, v.42, p.155-162, 1999.

RODRIGUES, P.B.; ROSTAGNO, H.S.; ALBINO, L.F.T.; GOMES, P.C.; BARBOZA, W.A.; SANTANA, R.T. Valores energéticos do milheto, do milho e subprodutos do milho, determinados com frangos de corte e galos adultos. Revista Brasileira de Zootecnia, v.30, p.1767-1778, 2001.

TAPSOBA, H.; WILSON, J.P. Effects of temperature and light on germination of urediniospores of the pearl millet rust pathogen, Puccinia substriata var. indica. Plant Disease, v.81, p.1049-1052, 1997.

WINKEL, T.; PAYNE, W.; RENNO, J.-F. Ontogeny modifies the effect of water stress on stomatal control, leaf area duration and biomass partitioning of Pennisetum glaucum. New Phytologist, v.149, p.71-82, 2001.

$\overline{\text { Recebido em } 4 \text { de agosto de } 2004 \text { e aprovado em } 6 \text { de maio de } 2005}$ 